Illinois State University

ISU ReD: Research and eData

Theses and Dissertations

3-6-2019

\title{
Hydration Knowledge and Intake in High School Student Athletes
}

Erin Ortiz

Illinois State University, erinsoccer1@gmail.com

Follow this and additional works at: https://ir.library.illinoisstate.edu/etd

Part of the Human and Clinical Nutrition Commons

\section{Recommended Citation}

Ortiz, Erin, "Hydration Knowledge and Intake in High School Student Athletes" (2019). Theses and Dissertations. 1055.

https://ir.library.illinoisstate.edu/etd/1055

This Thesis is brought to you for free and open access by ISU ReD: Research and eData. It has been accepted for inclusion in Theses and Dissertations by an authorized administrator of ISU ReD: Research and eData. For more information, please contact ISUReD@ilstu.edu. 
HYDRATION KNOWLEDGE AND INTAKE IN HIGH SCHOOL STUDENT ATHLETES

\section{ERIN ORTIZ}

\section{Pages}

Heat related illness is one of the leading causes of death in high school athletes. Proper hydration strategies have been shown to decrease heat related illness in college and professional athletes. However, limited research has been conducted on the hydration habits of high school athletes. The increase in high school sports participation has put more athletes at risk for dehydration. The purpose of this study is to investigate the hydration status and impact of an educational intervention on hydration habits of high school student athletes, by assessing their current understanding of hydration and monitoring their fluid intake, during practice. There is limited research on hydration habits of high school athletes.

Sixteen female high school tennis players participated in this study. Data was collected on the player's pre/post practice body weight and pre/post water bottle weight, during an initialsession, post-session, and follow-up session. During the initial-session, the researcher performed a series of educational sessions on hydration for the team and coaches. The researcher assessed hydration knowledge by giving participants replica hydration questionnaires at the beginning and conclusion of the study. A paired-sample t-test was used to compare differences in average weight change and percent weight change between the initial-session/post-session and initialsession/follow-up session. A paired-sample t-test was also used to analyze the average fluid ounces consumed and percent change in water bottle weight between initial-session/post-session 
and initial-session/follow-up session. A paired-sample t-test was used to assess the differences between the pre/post hydration questionnaire, body weight, and fluid intake.

There were no significant differences $(\mathrm{p}>0.05)$ between the initial-session and the postsession in regards to changes in percent body weight change or fluid intake. However, there were significant differences $(\mathrm{p}=0.006)$ in percent body weight change between the initial-session $(0.00 \pm 0.50 \%)$ and the one-month follow-up session $(-1.05 \pm 0.80 \%)$. Drinking habits during the follow-up session did not appear to be similar to the intervention period. Significant differences ( $p>0.001)$ were noted between the initial-session $(15.87 \pm 6.00 \mathrm{oz}$.$) and follow-up session (0.00 \pm$ 7.40oz.) in ounces of fluid consumed. The researcher found significant differences $(p=0.00)$ between the percent weight change in water bottles between the initial-session $(56.87 \pm 11.40 \mathrm{oz}$. $)$ and the follow-up session (27.25 $\pm 15.17 \mathrm{oz}$.). There were no significant differences between the results of the pre/post-hydration questionnaire.

The findings from this study indicated that participants were more aware of their drinking habits during the intervention period. Participants had similar drinking habits and saw less of a decrease in their post training percent body weight change in the initial-session and post-session. When researchers returned to the site to conduct their one-month follow-up session they found that participants drinking habits did not resemble the intervention period (initial/post-session). The teams overall fluid consumption had dropped and there were greater decreases in their post training percent body weight change. Many factors may have influenced changes in fluid consumption, but more research is needed on hydration status and the impact of hydration education in high school student athletes.

KEYWORDS: Dehydration, Female Athletes, Weight Loss, Fluid Intake, Heat-Related Illness 
HYDRATION KNOWLEDGE AND INTAKE IN HIGH SCHOOL STUDENT ATHLETES

ERIN ORTIZ

A Thesis Submitted in Partial

Fulfillment of the Requirements

for the Degree of

MASTER OF SCIENCE

Department of Family and Consumer Sciences

ILLINOIS STATE UNIVERSITY

2019 
Copyright 2019 Erin Ortiz 
HYDRATION KNOWLEDGE AND INTAKE IN HIGH SCHOOL STUDENT ATHLETES

ERIN ORTIZ

COMMITTEE MEMBERS:

Jennifer Barnes, Chair

Sally Arnett-Hartwick

Dale Brown 


\section{CONTENTS}

Page

$\begin{array}{lll}\text { TABLES } & \text { iii }\end{array}$

CHAPTER I: INTRODUCTION 1

$\begin{array}{ll}\text { Methodology } & 3\end{array}$

$\begin{array}{ll}\text { Participants } & 3\end{array}$

Experimental Design 3

$\begin{array}{ll}\text { Initial-Session } & 4\end{array}$

$\begin{array}{ll}\text { Educational Sessions } & 5\end{array}$

$\begin{array}{ll}\text { Post-Session } & 5\end{array}$

$\begin{array}{lr}\text { Follow-up Session } & 6\end{array}$

$\begin{array}{ll}\text { Statistical Analyses } & 6\end{array}$

$\begin{array}{ll}\text { Results } & 7\end{array}$

$\begin{array}{ll}\text { Pre/Post Body Weight } & 7\end{array}$

$\begin{array}{lr}\text { Pre/Post Water Bottle Weights (Fluid Intake) } & 8\end{array}$

$\begin{array}{lc}\text { Pre/Post Questionnaire Results } & 8\end{array}$

$\begin{array}{lr}\text { Discussion } & 9\end{array}$

CHAPTER II: LITERATURE REVIEW 28

Effects of Dehydration on Sports Performance 28

$\begin{array}{ll}\text { Fluid Recommendations on Youth Athletes } & 31\end{array}$

Previous Literature on Hydration Studies in Youth Athletes 35

$\begin{array}{ll}\text { REFERENCES } & 41\end{array}$

APPENDIX A: HYDRATION QUESTIONNAIRE 46 


\section{TABLES}

Tables

Page

1. Weather Data Collected During Study 13

2. Initial-Session Pre/Post Body Weight Averages 14

3. Post-Session Pre/Post Body Weight Averages 15

4. Follow-up Session Pre/Post Body Weight Averages 16

5. Differences In Average Weight Change and Percent Weight Change Initial-Session vs. Post-Session

6. Comparisons between Average Weight Change and Percent Weight Change Initial-Session vs. Post-Session

7. Average Weight Change and Percent Weight Change Initial-Session vs. Follow-up

8. Comparisons between Average Weight Change and Percent Weight Change Initial-Session vs. Follow-up Session

9. Initial-Session Water Intake and Water Bottle Weight Averages

10. Post-Session Water Intake and Water Bottle Weight Averages

11. Follow-up Session Water Intake and Water Bottle Weight Averages

12. Paired T-Test Initial-Session vs. Post-Session Average Water Intake and Percent Average Weight Change in Water Bottles

13. Paired T-Test Initial-Session vs. Follow-up Session Average Water Intake and Percent Average Weight Change in Water Bottles

14. Paired T-Test for Pre/Post Questionnaire Number and Percentage Correct 


\section{CHAPTER I: INTRODUCTION}

Participation in high school sports is on the rise (National Federation of State High School Associations, 2018). This increase in sports participation puts more athletes at risk for dehydration. Dehydration occurs when fluid losses are not properly replaced (Nuccio, Barnes, Carter, \& Baker, 2017). According to a report conducted by the Centers for Disease Control, (CDC) heat illness was the leading cause of death among high school athletes between 20052009 (Yard, Gilchrist, Haileyesus, Murphy, Collins, McIlvain, \& Comstock, 2010). Signs of heat illness begin to manifest with as little as a $1 \%$ decrease in body weight, due to dehydration. As a result, athletes may experience decreases in cognition, performance, and reaction time (McDermott et al., 2017; Rowland, 2011). Coaches, athletic trainers, and parents should take measures to educate students on proper hydration techniques; to help decrease heat related illness. The America Academy of Pediatrics recommends that children and adolescents should be regularly educated on proper hydration habits, and fluids should be easily accessible during practices and games (Bergeron, Devore, \& Rice, 2011).

Previous studies have shown that adolescents lack knowledge on hydration and they are failing to replenish fluid losses during and after practice. Many of the participants in these studies began practice in a dehydrated state (Arnaoutis et al., 2013; Arnaoutis et al., 2015; Gibson, Stuart-Hill, Pethick, \& Gaul, 2012; Phillips, Sykes, \& Gibson, 2014). The literature on hydration status in adolescent and youth athletes is growing; however, most past studies have focused their research on adult athletes. There is limited research in the United States on this topic (Arnaoutis et al., 2013; Arnaoutis et al., 2015; Gibson, Stuart-Hill, Pethick, \& Gaul, 2012; Phillips, Sykes, \& Gibson, 2014). The current research in the United States on this topic has centered on football. 
There are many ways to monitor hydration status. Measuring pre/post body weight is one of the best indicators of hydration status. Other studies used sweat rates and urine specific gravity (USG) as markers for dehydration (Arnaoutis et al., 2013; Arnaoutis et al., 2015; Gibson, Stuart-Hill, Pethick, \& Gaul, 2012; Phillips, Sykes, \& Gibson, 2014). Existing research on hydration status in youth and adult athletes has primarily been limited to a single occasion or a three-day period. These studies did not provide education on hydration techniques or follow-up with the participants. This current study was one of the first to include a one-month follow-up session and an educational intervention on hydration. The researcher monitored fluid intake and hydration status through pre/post body weight measurements and pre/post water bottle weight.

The purpose of this mixed-methods study was to educate high school athletes on fluid intake and increase their knowledge of proper hydration techniques. Due to the lack of information on hydration status among high school athletes, this study aims to add to the literature and promote future studies on hydration status in high school sports.

Two research questions were investigated during this study. The first research question was: are high school student athletes properly hydrating during and after practice? The second research question was: would this educational intervention help influence the hydration status of high school student athletes during practice? It was hypothesized that high school student athletes are not properly hydrating during and after practice. It was also hypothesized that the educational intervention would help influence the hydration status in high school student athletes during practice. 


\section{Methodology}

\section{Participants}

Institutional Review Board (IRB) approval was obtained prior to administration of this study, though Illinois State University's Office of Research Ethics and Compliance. The sample population was chosen by contacting local athletic directors and coaches via email. Approximately, 20 high school athletic directors and coaches in Central Illinois were contacted. My researcher received interest from two coaches. However, at the last minute one team had to drop out of the study due to changes in the coaching staff. Sixteen high school female tennis players participated in this study. The participants ranged between the ages of 14-18. The majority of the participants were high school sophomores.

\section{Experimental Design}

The researcher held an informational session with parents, coaches, and players prior to the administration of the study. During this informational session, the researcher provided participants, coaches, and parents with a verbal explanation of the study. Written parental informed consent and minor assent was obtained, at the informational session. All participants completed the pre-hydration questionnaire and initial-session; however; due to school conflicts, not all the participants were able to complete the follow-up session. Only nine participants completed the follow-up session.

A longitudinal mixed methods research design was implemented. Participants who agreed to take part in this study were given a 32-ounce Nalgene water bottle as compensation. Each water bottle was labeled with an identification code that the players used as their ID throughout the study. Students were instructed to bring these water bottles to practice, to measure their fluid intake. Participants completed a pre-test hydration questionnaire at the informational 
session (see Appendix A for complete questionnaire). The researcher modified their questionnaire based on previous studies that had been conducted on hydration (Trammell, 2007). The pre/post hydration questionnaire contained two sections. The first section gathered background information on the participant's grade level and practice habits. The second part consisted of a series of True/False questions and short answer questions. Participant's hydration status was observed and measured using a water bottle during the initial-session, post-session, and follow-up session. Participants pre/post practice body weight was collected during the initial-session, post-session, and the follow-up session.

\section{Initial-Session}

The initial-session took place during mid-August. The researcher collected and monitored the player's hydration status and weight during two typical, 2-hour training sessions, which were two days apart. Players were weighed pre/post practice to measure changes in body mass. Body weight has been shown to be one of the best indicators of hydration status (Gibson, Stuart-Hill, Pethick, \& Gaul, 2012). At the beginning of practice, players were asked to weigh in on a Healthometer Split Mat Digital Scale. Body weight was recorded to the nearest 0.1 pound. Participants were encouraged to void their bladders before practice, but the researcher was unable to enter the school prior to practice and could not monitor this factor. Players left immediately after practice and did not void their bladders at the school. Players remained clothed with shoes and socks during weigh-ins. Pre-water bottle weight was taken at the same time as pre-body weight. Before participants stepped onto the scale, they placed their water bottle onto a Taylor Stainless Steel Scale. The Taylor Scale was calibrated before each session, to set the reading at 0.0 grams. The weight of each water bottle was recorded to the nearest gram. The researcher remained on the tennis courts to monitor water breaks and fluid intake. The researcher 
took notes on water brakes and fluid refills. The participants did not refill their water bottles during practice because no water foundation was located near the tennis courts. At the end of practice, players were asked to step back on the scale and weigh their water bottle. Pre-practice and post-practice weight were calculated using the following equation: \%body mass loss= (prebody mass_-post-body mass)/pre-body mass *100 (Gibson, Stuart-Hill, Pethick, \& Gaul, 2012). A body weight loss greater than $1 \%$ was indicative of dehydration (Arnaoutis et al., 2015). Water bottle weight was measured using the equation: (pre-water bottle weight-post-water bottle weight $)=$ total fluid consumed in practice.

\section{Educational Sessions}

The educational sessions on hydration were held during the initial-session. Information regarding the educational sessions can be found in Appendix B. The coach agreed to end practice fifteen minutes early on both days. The sessions were held in the high school practice gym. Participants gathered around the researcher's computer and listened to a PowerPoint presentation. The sessions lasted between 10-15 minutes. Three topics were covered including signs and symptoms of dehydration, proper hydration techniques for athletes, and monitoring/increasing fluid intake were held during the initial-session. The researcher provided handouts for the students including a urine color chart and a chart created by the Academy of Nutrition and Dietetics on individualized hydration intake. Participants and coaches were encouraged to ask questions during these educational sessions.

\section{Post-Session}

One week following the initial-session, the researcher returned to the high school tennis courts to conduct the post-session. The researcher collected and monitored the players' hydration status and weight during two typical, 2- hour training sessions, which were two days apart. The 
researcher followed the same protocols for collecting body weight and water bottle weight as in the initial-session. No educational hydration sessions were held during the post-session.

\section{Follow-up Session}

The follow-up session was executed one month following the initial-session. The purpose of the follow-up session was to test the validity of the study and to determine if the hydration intervention was successful. The researcher returned to the high school tennis courts to gather information on pre/post body weight and water bottle weight. The follow-up session took place mid-tennis season. At this time in the season, the coaches shortened the practices to 1 hour and 15 minutes to give the players more recovery time. Only half of the team participated in the follow-up session. The high school juniors and seniors had prior engagements for school. Nine participants completed the follow-up session. The researcher collected body weight and water bottle weight during the first follow-up session. The researcher followed the same protocols for gathering data as in the previous pre/post sessions. During follow-up session two, players weight was not collected, but participants were given the post-hydration questionnaire (see Appendix A for complete questionnaire). The post-hydration questionnaire was identical to the pre-hydration questionnaire. The participant's pre/post questionnaire answers were compared and tested for reliability. The hydration questionnaires also assessed the participant's hydration knowledge at the beginning and end of the study.

\section{Statistical Analyses}

The data collected from this study was analyzed using SPSS and Microsoft Excel. Data collected on pre/post body weight and pre/post water bottle weight was entered into Microsoft Excel spreadsheets. The Excel sheets were formulated to calculate the body weight change, \%body weight change, and fluid ounces consumed. This data was entered into SPSS to look for 
any significant changes between the pre/post and follow-up sessions. At the same time, a paired t-test was run using SPSS to gauge the effectiveness of the hydration intervention and its impact on fluid intake. The pre/post questionnaire contained seven questions that were graded. The number correct and percentage correct for the pre/post questionnaire were entered into SPSS. A paired t-test was run to compare the participant's pre/post-test multiple choice selections.

\section{Results}

Sixteen high school female tennis players participated in this study. The athletes ranged in age from 14-18 years old. One player completed the initial session but did not complete the post-session or follow-up session. Two players joined the study on the first day of practice. The researcher was only able to collect pre/post weight once during the follow-up session, due to conflicts with the team's schedule. During the follow-up session, body weight and fluid intake was collected on nine participants. The high school juniors and seniors had prior commitments for school. In addition to data collection, the researcher kept notes on the weather conditions during practice (Table 1). Similar weather conditions were observed at each practice.

\section{Pre/Post Body Weight}

The differences in average weight change for each session are shown in Tables 2-4. When looking at individual participant's data, most of players lost between $0 \%-2 \%$ of their body mass. Improvements were seen in the combined team average percent weight loss between the pre-session and post-session. There were no significant differences found between the initialsession and post-session for average weight change or percent weight change. Table 6 shows the team's average weight change for the initial-session $(0.20 \pm 0.831 \mathrm{bs}$.) and the post-session was $(0.23 \pm 0.641 \mathrm{bs}$. $)$. During the follow-up, there was a significant difference in the percent weight change between the pre-session and the follow-up session. The average weight change for the 
pre-session was $(0.20 \pm 0.83 \mathrm{lbs}$. $)$ and the follow-up $(0.84 \pm 1.05 \mathrm{lbs}$. $)$ can be seen in Table 8 . The percent weight change between the pre-session $(0.00 \pm 0.50 \%)$ and the follow-up session $(-1.05 \pm 0.80 \%)$ was found to be statistically significant $(\mathrm{p}=0.006)$.

\section{Pre/Post Water Bottle Weights (Fluid Intake)}

A wide range of fluid volumes were consumed. Tables 7-9 reveal the drinking habits of the participants in this study. During the follow-up session, five players substituted their water intake with a sports drink. Water bottle weights were converted from grams to ounces using the following correction factor. Weight Change -180 (weight of empty water bottle)/28.93. Percent weight change was calculated by dividing the post-water bottle weight by the pre-water bottle weight. There was a statically significant difference between the average percent weight change between initial-session and the post-session $\mathrm{p}<0.001$ (Table 12). Table 13 shows that the average ounces consumed $(\mathrm{p}<0.001)$ and average percent weight change $(\mathrm{p}<0.05)$ were statistically significant between the initial-session and the follow-up session.

\section{Pre/Post Questionnaire Results}

The participants' True/False answers from the pre/post hydration questionnaire were compared after the study completed, to look for trends. The results did not present any significant differences between answers in the pre/post-test (Table 14). Even though none of the multiple-choice questions appeared to have statistical significance, pair six and seven did show a trend with a p-value of 0.082 (Table 15). Many of the participants' scores remained the same between the pre-survey and post-survey. On the post-survey, the first multiple-choice question was the number one question that was answer incorrectly. The correct answer is true, but 10 participants selected false. 


\section{Discussion}

This present study is one of the first assessments of high school female athletes that utilized both an educational intervention while monitoring change in fluid intake and percent body weight. The findings of this study suggests that drinking habits of high school athletes needs to be further investigated to establish standards for dehydration. A few athletes experienced a percent body mass loss of greater than $2 \%$, which has been associated with decreases in performance and cognition (Travis, T., Erdman, K.A, \& Burke, L.M, 2016). The athletes in this study did not appear to have decreases in performance, but the researcher was only monitoring hydration status. Other studies on adolescent athletes have found similar results, regarding weight loss during practice. Many of the athletes in these studies began practice in a dehydrated state and maintained this status throughout the practice (Bergeron, Waller, \& Marinik, 2006; Gibson, Stuart-Hill, Pethick, \& Gaul, 2012; Phillips, Sykes, \& Gibson, 2014).

One of the prominent findings from this study was the drinking behaviors of the participants, during the initial-session and the follow-up session. There was a decrease in average ounces consumed $(\mathrm{p}<0.0001)$ and the percent weight change in water bottle weight $(\mathrm{p}=0.005)$. These findings suggest that players may have reverted to their pre-study drinking habits after the conclusion of post-session. This may infer that during the initial-session and post-session participants many have been more aware of their drinking habits and consumed more fluids than during the follow-up session. These results are different from the findings found by Bergeron et al. (2006), which found there were no significant differences in fluid intake between trials.

Both this current study and the study by Bergeron et al. (2006) found that the percent weight changes between trials were significant. In both studies, participants had the greatest differences in their percent body weight change during the follow-up session. Participants had a 
larger decrease in percent body weight lost at the end of practice during the follow-up session than during the initial-session and post-session. These results suggest that players may not be properly hydrating during the tennis season and more education on hydration may be needed. It may also be important to provide educational opportunities to teach parents and coaches about hydration guidelines for youth athletes. Youth athletes many also benefit from personalized hydration plans. Studies in Italy and the United States showed that personalized hydration plans help reduced body mass losses during practice and helped improved performance during practices and games (Francescato et al., 2019; McDermott et al., 2009).

Hydration status may have been influenced by many factors. The players arrived at practice after a full day of school and other school related activities. Previous studies conducted on adolescent athletes have taken place during the summer months when school was not in session or in controlled environments. In addition, since past studies have focused on elite athletes, these athletes practice year-round and many may not attend school regularly. The drinking habits of elite athletes many be different than non-competitive youth athletes. Elite athletes may have better access to resources about hydration and fluid intakes. The participants used in this study were non-elite high school female student athletes. Hydration education had not been provided to this team prior to this study.

Many of the players reported on their pre/post hydration questionnaire that they received most of their information regarding hydration from sources other than Registered Dietitians and certified health professionals. The most common sources were their parents and the internet. The participants answers suggest that they are relying on sources that may not be providing the athletes with the most accurate information regarding hydration. This helps advocate the importance Registered Dietitians have in the sports nutrition world. 
The only significant finding between the initial-session and follow-up session one was the percent average weight change in the water bottle weight $(\mathrm{p}=0.006)$. Percent weight loss was not found to be significant between the initial-session and follow-up session, but many of the players did have a decrease in their post practice weight loss (Tables 2-5). This data is encouraging because players may have been more cognizant of the drinking habits right after the educational sessions on hydration.

Even though there were no significant findings between the pre/post hydration questionnaire; a trend was seen in pair six and seven $(\mathrm{p}=0.082)$. It may have been beneficial to review the educational sessions before the participants took the post hydration questionnaire. Many of the players rushed through the post hydration questionnaire so they could get to practice on time. It should also be noted that two of the participants were foreign exchange students and English was not their first language. In future studies, it may be beneficial to have the questionnaire and educational sessions available in multiple languages.

Limitations of this study included the small sample size. Only 16 students participated and only female athletes were used for this study. It would be better to have a larger sample size and include both genders in future studies, so these results can be extrapolated to a larger population. Participants were not instructed to use the bathroom prior to or after practice was over. Players may have seen differences in weight if this had occurred. Many other studies on elite youth athletes have used urine specific gravity as one of their markers to indicate hydration status (Phillips et al., 2014; Gibson et al., 2013; Kavouras et al., 2012; Arnaoutis et al., 2015). This longitudinal study took place across the span of a month. However, future studies would benefit from longer time periods. It would be beneficial to follow high school athletes throughout the entire season to note differences in fluid intake and pre/post weight. Parents were not 
involved with this study. Since, many of the participants specified that they received most of their hydration knowledge from their parents, it would be beneficial to include them in future studies.

The findings from this study provide evidence that more research is needed on hydration status in high school athletes. In addition, future studies should be completed over a longer duration and include parental education. It also may be beneficial to examine the players fluid intake during competitions; these results may better demonstrate the differences in fluid intake and body weight. More effective guidelines need to be developed for high school athletescurrent sports nutrition guidelines only pertain to individuals over the age of 18 . With the rise in high sports participation, it is crucial that guidelines are established for high school student athletes. 
Table 1. Weather Data Collected During Study

\begin{tabular}{|c|c|}
\hline Training Session & Temperature \\
\hline Initial-session 1 & $79^{\circ} \mathrm{F}$ with clouds \\
\hline Initial-session 2 & $82^{\circ} \mathrm{F}$ with humidity, partly cloudy \\
\hline Post-Session 1 & $82^{\circ} \mathrm{F}$, windy, partly cloudy \\
\hline Post-Session 2 & $80^{\circ} \mathrm{F}$ \\
\hline Follow-up 1 & $88^{\circ} \mathrm{F}$, windy, partly cloudy \\
\hline
\end{tabular}


Table 2: Initial-Session Pre/Post Body Weight Averages

\begin{tabular}{|c|c|c|}
\hline ID number & Averages Weight Change & Average \%Weight Change \\
\hline HS405 & 0 & $0 \%$ \\
\hline HS504 & -0.1 & $0 \%$ \\
\hline HS605 & 0.2 & $0 \%$ \\
\hline HS706 & 0.2 & $0 \%$ \\
\hline HS810 & 0.6 & $1 \%$ \\
\hline HS900 & -0.5 & $0 \%$ \\
\hline HS423 & 2.2 & $2 \%$ \\
\hline HS533 & -0.8 & $0 \%$ \\
\hline HS760 & 0.8 & $1 \%$ \\
\hline HS870 & -1.3 & $-1 \%$ \\
\hline HS960 & 0.1 & $0 \%$ \\
\hline HS473 & 0.4 & $0 \%$ \\
\hline HS584 & -0.4 & $0 \%$ \\
\hline HS613 & 1 & $1 \%$ \\
\hline HS655 & 0.6 & $0 \%$ \\
\hline Team Average & 0.3 & $1.0 \%$ \\
\hline
\end{tabular}


Table 3: Post-Session Pre/Post Body Weight Averages

\begin{tabular}{|c|c|c|}
\hline ID number & $\begin{array}{c}\text { Average Weight } \\
\text { Change }\end{array}$ & Average \%Weight Change \\
\hline HS405 & 0 & $0.0 \%$ \\
\hline HS504 & -0.3 & $-0.2 \%$ \\
\hline HS605 & 0.6 & $0.6 \%$ \\
\hline HS706 & 1.1 & $1.0 \%$ \\
\hline HS810 & 0.7 & $0.6 \%$ \\
\hline HS900 & -0.8 & $-0.7 \%$ \\
\hline HS423 & 1.5 & $1.1 \%$ \\
\hline HS533 & 0.4 & $0.2 \%$ \\
\hline HS760 & 0.6 & $0.4 \%$ \\
\hline HS870 & -0.4 & $-0.3 \%$ \\
\hline HS960 & -0.4 & $-0.3 \%$ \\
\hline HS473 & -0.3 & $-0.2 \%$ \\
\hline HS584 & 0 & $0.0 \%$ \\
\hline HS655 & 0.5 & $0.5 \%$ \\
\hline HS613 & 0 & $0.0 \%$ \\
\hline Team & 0 & $0.0 \%$ \\
\hline Average & & \\
\hline & 0.4 & \\
\hline
\end{tabular}


Table 4: Follow-up Session Pre/Post Body Weight Averages

\begin{tabular}{|c|c|c|}
\hline ID number & $\begin{array}{c}\text { Average Weight } \\
\text { Change }\end{array}$ & Average \% Wt. Change \\
\hline HS504 & 1.6 & $-1.2 \%$ \\
\hline HS605 & 0 & $0.0 \%$ \\
\hline HS706 & 0.8 & $-0.7 \%$ \\
\hline HS810 & 0.2 & $-0.2 \%$ \\
\hline HS533 & 2 & $-1.1 \%$ \\
\hline HS655 & 1.4 & $-1.0 \%$ \\
\hline HS870 & 1 & $-0.8 \%$ \\
\hline HS960 & 3 & $-2.5 \%$ \\
\hline HS584 & 2.6 & $-2.0 \%$ \\
\hline
\end{tabular}


Table 5. Differences in Average Weight Change and Percent Weight Change Initial-Session vs. Post-Session Paired Samples Test

\begin{tabular}{|c|c|c|c|}
\hline Paired Samples & Mean & Std. & Sig (2-Tailed) \\
& & Deviation & \\
\hline Pair 1: Average & -0.03 & 0.64 & 0.844 \\
Weight Change & & & \\
\hline Pair 2: Percent & 0.08 & 0.60 & 0.584 \\
Weight Change & & & \\
\hline
\end{tabular}


Table 6. Comparisons between Average Weight Change and Percent Weight Change Initial-Session vs. Post-Session

\begin{tabular}{|l|l|c|c|c|}
\hline \multicolumn{2}{|c|}{ Paired Samples } & Mean & Number & Std. Deviation \\
\hline Pair 1 & Avgwtchange & .200 & 15 & .8281 \\
\cline { 2 - 5 } & Avgwtchange1 & .233 & 15 & .6433 \\
\hline Pair 2 & Perwtchange & .267 & 15 & .7037 \\
\cline { 2 - 5 } & Perwtchange1 & .180 & 15 & .5102 \\
\hline
\end{tabular}


Table 7. Average Weight Change and Percent Weight Change Initial-Session vs. Follow-up Paired Samples Test

\begin{tabular}{|c|c|c|c|}
\hline Paired Samples & Mean & $\begin{array}{c}\text { Std. } \\
\text { Deviation }\end{array}$ & Sig (2-Tailed) \\
\hline Pair 1: Average & -0.64 & 1.60 & 0.141 \\
Weight Change & & 0.86 & $* 0.006$ \\
\hline $\begin{array}{c}\text { Pair 2: Percent } \\
\text { Weight Change }\end{array}$ & 1.05 & & \\
\hline
\end{tabular}

*p-value set at 0.05 
Table 8. Comparisons between Average Weight Change and Percent Weight Change Initial-Session vs. Follow-up Session Paired Samples Statistics

\begin{tabular}{|l|c|c|c|c|}
\hline \multicolumn{2}{|c|}{ Paired Samples } & Mean & Number & Std. Deviation \\
\hline Pair 1 & AverageWtCh & .200 & 15 & .8281 \\
\cline { 2 - 5 } & AverageWtCh1 & .840 & 15 & 1.0480 \\
\hline Pair 2 & Peravgwtchange & .000 & 9 & .5000 \\
\cline { 2 - 5 } & Peravgwtch1 & -1.052 & 9 & .7989 \\
\hline
\end{tabular}


Table 9. Initial-Session Water Intake and Water Bottle Weight Averages

\begin{tabular}{|c|c|c|}
\hline Water Bottle ID & $\begin{array}{c}\text { Average Water Intake } \\
\text { (ounces) }\end{array}$ & $\begin{array}{c}\text { Average Percent Weight } \\
\text { Change }\end{array}$ \\
\hline HS405 & 17 & 60 \\
\hline HS504 & 21 & 66 \\
\hline HS605 & 15 & 51 \\
\hline HS706 & 13 & 50 \\
\hline HS810 & 15 & 51 \\
\hline HS900 & 3 & 24 \\
\hline HS423 & 23 & 77 \\
\hline HS533 & 17 & 57 \\
\hline HS760 & 19 & 63 \\
\hline HS870 & 14 & 52 \\
\hline HS960 & 27 & 81 \\
\hline HS473 & 18 & 67 \\
\hline HS584 & 13 & 47 \\
\hline HS777 & 8 & 37 \\
\hline
\end{tabular}


Table 10. Post-Session Water Intake and Water Bottle Weight Averages

\begin{tabular}{|c|c|c|}
\hline $\begin{array}{c}\text { Water Bottle } \\
\text { ID }\end{array}$ & $\begin{array}{c}\text { Average Water Intake } \\
\text { (ounces) }\end{array}$ & $\begin{array}{c}\text { Average Percent Weight } \\
\text { Change }\end{array}$ \\
\hline HS405 & 14 & 20 \\
\hline HS504 & 15 & 32 \\
\hline HS605 & 15 & 33 \\
\hline HS706 & 20 & 52 \\
\hline HS810 & 19 & 39 \\
\hline HS900 & 8 & 16 \\
\hline HS423 & 15 & 42 \\
\hline HS533 & 5 & 28 \\
\hline HS655 & 19 & 43 \\
\hline HS760 & 11 & 31 \\
\hline HS870 & 7 & 17 \\
\hline HS960 & 17 & 33 \\
\hline HS473 & 7 & 11 \\
\hline HS584 & 15 & 44 \\
\hline HS613 & 7 & 41 \\
\hline & & \\
\hline
\end{tabular}


Table 11. Follow-up Session Water Intake and Water Bottle Weight Averages

\begin{tabular}{|c|c|c|}
\hline $\begin{array}{c}\text { Water Bottle } \\
\text { ID }\end{array}$ & $\begin{array}{c}\text { Average Water Intake } \\
\text { (ounces) }\end{array}$ & $\begin{array}{c}\text { Average Percent Weight } \\
\text { Change }\end{array}$ \\
\hline HS504 & 0 & 15 \\
\hline HS605 & 6 & 29 \\
\hline HS706 & -1 & 13 \\
\hline HS810 & 16 & 54 \\
\hline HS533 & 14 & 46 \\
\hline HS870 & 0 & 15 \\
\hline HS960 & 3 & 22 \\
\hline HS584 & 4 & 24 \\
\hline
\end{tabular}


Table 12. Paired T-Test Initial-Session vs. Post-Session Average Water Intake and Percent Average Weight Change in Water Bottles

\begin{tabular}{|c|c|c|c|}
\hline Paired Samples & Mean & Std. Deviation & Sig. (2-Tailed) \\
\hline Pair 1: Average & 2.93 & 7.66 & 0.160 \\
Ounces Water & & & \\
Consumed & & & \\
\hline Pair 2: Average & 26.77 & 17.65 & 0.000 \\
Percent Change & & & \\
in Water Bottle & & & \\
Weight & & & \\
\hline
\end{tabular}

*p-value set at 0.05 
Table 13. Paired T-Test Initial-Session vs. Follow-up Session Average Water Intake and Percent Average Weight Change in Water Bottles

\begin{tabular}{|c|c|c|c|}
\hline Paired Samples & Mean & Std. Deviation & Sig. (2-Tailed) \\
\hline Pair 1: Average & 15.87 & 8.98 & 0.000 \\
Ounces Water & & & \\
Consumed & & & \\
\hline $\begin{array}{c}\text { Pair 2: Average } \\
\text { Percent Change } \\
\text { in Water Bottle } \\
\text { Weight }\end{array}$ & 29.63 & 20.50 & 0.005 \\
\hline
\end{tabular}

*p-value set at 0.05 
Table 14. Paired T-Test for Pre/Post Questionnaire Number and

\section{Percentage Correct}

\begin{tabular}{|c|c|c|c|}
\hline Paired Samples & Mean & Std. Deviation & Sig. (2-Tailed) \\
\hline Pair 1: Number & 0.23 & 0.83 & 0.337 \\
Correct & & & \\
\hline $\begin{array}{c}\text { Pair 2: Percent } \\
\text { Correct }\end{array}$ & 7.07 & 17.56 & 0.172 \\
\hline
\end{tabular}

*p-value set at 0.05 
Table 15. Comparisons between Pre/Post Test Multiple Choice Questions.

\begin{tabular}{|c|c|c|c|}
\hline Paired Samples & Mean & Std. Deviation & Sig. (2-Tailed) \\
\hline $\begin{array}{l}\text { Pair 1: Hours } \\
\text { practiced per day }\end{array}$ & -0.08 & 0.49 & 0.584 \\
\hline $\begin{array}{l}\text { Pair 2: Intensity of } \\
\text { Practice }\end{array}$ & -0.15 & 0.376 & 0.165 \\
\hline $\begin{array}{l}\text { Pair 3: Best Gauge } \\
\text { of dehydration }\end{array}$ & -0.31 & 0.63 & 0.140 \\
\hline $\begin{array}{l}\text { Pair 4: Dehydration } \\
\text { and Performance }\end{array}$ & 0.08 & 0.28 & 0.337 \\
\hline $\begin{array}{l}\text { Pair 5: Drink Water } \\
\text { During Practice }\end{array}$ & 0.08 & 0.28 & 0.337 \\
\hline $\begin{array}{l}\text { Pair 6: Signs of } \\
\text { Dehydration }\end{array}$ & 0.23 & 0.44 & 0.082 \\
\hline $\begin{array}{l}\text { Pair 7: Are sports } \\
\text { drinks better than } \\
\text { water }\end{array}$ & 0.23 & 0.44 & 0.082 \\
\hline $\begin{array}{l}\text { Pair 9: Determine } \\
\text { Weight }\end{array}$ & 0.17 & 0.39 & 0.166 \\
\hline $\begin{array}{l}\text { Pair 10: I believe I } \\
\text { stay hydrated when I } \\
\text { start practice }\end{array}$ & 0.17 & 0.58 & 0.339 \\
\hline
\end{tabular}




\section{CHAPTER II: LITERATURE REVIEW \\ Effects of Dehydration on Sports Performance}

In 2010, a report conducted by the Centers for Disease Control found the leading cause of death and disabilities in high school student athletes was heat related illness (Yard et al., 2010). These findings along with heat acclimation guidelines from the National Athletics Trainer's Association (NATA) have helped promote the importance of educating high school athletes about hydration status and dehydration. NATA recommends that high school coaches implement a 14-day heat acclimation period for summer/fall sports. During the first five days, teams should be limited to one practice that last no longer than 3 hours. Sports that required protective equipment can only permit the use of helmets for the first 1-3 days of practice and full equipment should not be worn until day six. When two practices are held in one day, a three-hour break period must be given between practices (Casa et al., 2009).

These guidelines can help reduce heat related illness. The increase is sports over the past ten years emphasizes the importance of carrying out NATA's guidelines, to prevent heat related illnesses in youth athletes. In 2018, The National Federation of State High School Associations (NHFS) reported, nearly eight million high school students participated in sports programs (NHFS, 2018). This increase in sports participation puts more students at risk for dehydration because student athletes may lack knowledge on hydration and the signs and symptoms of dehydration.

Previous research on youth and adult athletes has indicated that athletes are not properly hydrating throughout the day. However, many of these studies have not attempted to educate athletes on proper hydration techniques. Maintaining a hydrated status is vital to sports performance. The human body is $70-80 \%$ water. Water plays an important role in the body. It 
regulates body temperature, keeps tissue moist, lubricates joints, and hydrates muscles. Every system in our body is dependent on water (Meyer, Volterman, Timmons, \& Wilk, 2012). In fact, we will die after a few days if we do not have water. It is important for athletes to replenish fluid losses, not only during games and practices, but consistently though out the day.

During exercise, the core temperature of the body rises. Exercising in hot and humid temperatures can cause a $2-3^{\circ} \mathrm{C}$ rise in core body temperature. This rise in body temperature can lead to heat exhaustion if the proper measures are not taken (Maughan \& Shirreffs, 2010). The body naturally compensates for a temperature increase during exercise by sweating. When athletes fail to replenish sweat losses, dehydration can occur. When the body is dehydrated, our plasma and blood volumes drop (hypovolemia), which places strain on our cardiovascular system, central nervous system, and leads to a rise in our body temperature (Travis, T., Erdman, K.A., \& Burke, L.M., 2016). Proper hydration strategies can help offset dehydration and restore our bodies to a healthy state. Athletes can learn to recognize when they are becoming dehydrated through education and learning how their bodies react in humid environments. Coaches and athletic trainers can assist by making fluids readily available to athletes during practices (Bergeron, Devore, \& Rice, 2011).

Youth and adolescents are more susceptible to dehydration. They have underdeveloped thermoregulation systems causing decreased sweat rates and increased core temperatures during exercise. Young athletes have a greater surface area for their body weight and do not fare well in high heat. The most significant factor that increases their risk of dehydration is failing to recognize when they feel thirsty (Sawka, Cheuvront, \& Carter, 2005). Youth athletes are most at risk for dehydration and heat related illnesses during the summer months. The American Academy of Pediatrics (2011) defined heat exhaustion as a moderate heat illness in which an 
individual is unable to maintain blood pressure and adequate cardiac output. This can result from strenuous exercise or physical activity when temperatures are above $40^{\circ} \mathrm{C}\left(104^{\circ} \mathrm{F}\right)$. On the other hand, exertional heat stoke can occur when the core body temperature climbs above $40^{\circ} \mathrm{C}$ (Bergeron, Devore, \& Rice, 2011).

A special report from the Centers for Disease Control (2010) reviewed heat related illness in high school athletes around the country. They found that during the month of August, athletes were most likely to experience heat related illnesses. They warned that high school football players are ten times more likely to suffer from a heat related illness compared to other high school athletes (Yard et al., 2010). They added that obesity and increased body weight in football players escalated their risk of heat illness. Excess body fat decreases heat loss and increases core body temperature in athletes. This factor can cause issues for any athlete that is overweight or obese. Moyen et al. (2016) found that obese females had lower chest-sweat sensitivity compared to non-obese females during passive heat stress. If athletes are properly hydrating during practices and games, they are at an increased risk of developing heat illness. Heat illness can be reduced if student athletes are given time to acclimate to the heat and are educated on hydration (McDermott et al., 2017).

NATA recommends that athletes should be given seven to fourteen days to acclimate to the heat. This process involves gradually increasing the intensity and duration of the physical activity. These guidelines are especially important during the first few weeks of the season (McDermott et al., 2017). Dehydration is not limited to hot weather. During the winter, water is lost through heat exchange by the lungs. In the winter, our thirst mechanisms are diminished. Athletes who participate in summer and winter sports should follow the same fluid recommendations throughout the year (Sawka, Cheuvront, \& Carter, 2005). 
Armstrong et al. (1998) suggested that preventing dehydration beings with educating student athletes. One simple way to educate young athletes on hydration status is with a urine test. Athletes will learn to recognize hydration status through their urine color. The researchers of this article provided ways their results could be used in practical applications. They suggested that if athletes achieve a clear to pale yellow urine color after practice they will reduce the effects of dehydration (Armstrong et al., 1998).

\section{Fluid Recommendations on Youth Athletes}

Research has shown that a body water loss of 1-2\% causes an increase in body temperature. This equates to 1.5 to 3 pounds for athletes weighing 150 pounds. If body water losses exceed 3\%, athletes may experience decreases in performance, cramps, and medical complications: heat stroke, heat exhaustion, or death (Meyer, Volterman, Timmons, \& Wilk, 2012). A review on college and professional athletes found that signification dehydration (>2\% body mass loss) was linked to decreases in performance, cognition, coordination, and reaction time (Nuccio, Barnes, Carter, \& Baker, 2017). Nuccio et al. (2017) discovered that soccer players reported the more significant dehydration rates ( $>2 \%$ body mass loss) compared to professional adult rugby, America football, basketball, and tennis players.

A study on trained cyclists contradicted the current guidelines regarding hydration. The participants participated in three phases: dehydration, rehydration, and time trial. Each phase was separated by six days to avoid acclimation to the environment. In the dehydration phase participants achieved a percent body mass loss of $3 \%$ before entering the rehydration phase. During the rehydration phase, participants received an infusion of saline containing sodium, potassium, magnesium, and chloride at $100 \%$ of their change in body mass (euhydration), $33 \%$ of their change in body mass ( $2 \%$ hypohydration) or no saline ( $3 \%$ hypohydration). After they 
completed the rehydration phase, study participants completed a $25 \mathrm{~km}$ cycling time trial. The researcher compared the time trail completion times between the three groups. Hydration was achieved during the time trial by using the same amount of saline from the rehydration period. No differences were noted between the three groups. The $2 \%$ hypohydration and $3 \%$ hypohydration groups finished the time trail 0.02-0.03 seconds faster than the euhydration group. The results from this study showed that hydration status did not have an effect on aerobic performance (Wall et al., 2015).

However, the results from Walls study may not translate to endurance athletes who are shown to be at an increased risk for dehydration, due to higher sweat losses during exercise (Maughan \& Shirreffs, 2010). Many youth and adolescent athletes participate in endurance sports and may be unaware of ways to monitor \%body mass loss. Many studies have utilized pre/post body weight by using the following equation: $\%$ body mass loss= (pre-body mass - post body mass)/pre-body mass* 100) (Gibson, Stuart-Hill, Pethick, \& Gaul, 2012). The National Federation of State High School Associations and Sports Medicine Advisory Committee (2014) endorsed that all student athletes should be weighed before and after warm or hot weather practices. They recommend that students should be weighed in shorts and a t-shirt. Coaches and athletic trainers can use this information to monitor their team's dehydration status throughout practice and the season (NFHS, 2014). The objective of pre/post body weight is to educate athletes about the best ways to try and maintain their body weight during practice. Calculating fluid intake for student athletes is based on many factors including: age, body size, diet, sweat volume, and health conditions (American Academy of Pediatrics, 2011). The Academy of Nutrition and Dietetics has not published a position paper on hydration guidelines for youth and adolescents, but they have provided recommendations for hydration intake on 
event days. Athletes should drink 12-22 ounces of cool water approximately 1-2 hours prior to the event. A few minutes before the event starts they should drink about 10-20 ounces of cool water. During the event, they should try to consume 4-6 ounces every 15 minutes. After the event, they should rink 16-24 ounces for every pound they have lost (Academy of Nutrition and Dietetics Nutrition Care Manual, 2018).

Other recommendations for fluid intake in adolescent athletes include the Dietary Reference Intakes (DRIs) for water in 14-18 years old: 10 cups for females and 14 cups for males. Active adolescents may need more depending on their activity level. The American Academy of Pediatrics (AAP) recommends that adolescents between the ages of 14-18 years old, consume 9-13 ounces of water every 15 minutes during practice. This equates to $36-52$ ounces (4.5 -6.5 glasses of water) per hour. Water intake should not be limited to practices and games. Athletes should be encouraged to consume and additional 6-8 cups of water every day (AAP, 2011).

However, other research suggests that fluid guidelines for adolescents during exercise should be $13 \mathrm{~mL} / \mathrm{kg}$ (6 mL/lb.) for every hour of exercise. For a $150 \mathrm{lb}$. (69.2 kg) athlete, this equates to approximately $890 \mathrm{~mL} / \mathrm{hr}$. or $30 \mathrm{oz} / \mathrm{hr}$. (Rowland, 2011). Maintaining a hydrated state should not stop after practice. Rowland (2011) suggested that student athletes should be replenishing fluid losses post workout at a rate of $4 \mathrm{~mL} / \mathrm{kg}(2 \mathrm{~mL} / \mathrm{lb}$.) per hour. If athletes fail to restore lost fluids post workout, the next day they may start practice in a dehydrated state. Athletes who begin practice in a dehydrated state are at great risk for developing heat related illness (Poole, Stearns, \& Lopez, 2017). Coaches, athletic trainers, and parents should encourage regular fluid intake throughout the day to help prevent heat related illness. 
Even though student athletes may reach for thirst quenching sport and energy drinks, the American Academy of Pediatrics recommends that water should be the number one choice for replenishing fluids for adolescents (AAP, 2011). Water is the best choice for adolescent and youth athletes that exercise less than 90 minutes. If young athletes are not keen on drinking plain water, they can boost the flavor of plain water by adding fruit or a low-sugar liquid water enhancer. Sports drinks can be useful during periods of excessive heat and intense exercise. Sport drinks are enhanced with electrolytes sodium and potassium, as well as carbohydrates to help refuel muscle glycogen levels and help postpone fatigue. However, they should complement a student athlete's water intake. Adolescent tennis players observed in a crossover design study comparing water intake and carbohydrate/electrolyte drinks (CHO-E) were followed during a three-week training session. The CHO-E drinks were found to lower core temperature better than water (Bergeron et al., 2006). Moreover, it should be noted that mean fluid intake of CHO-E drinks was greater than water, but participants also noted great gastrointestinal discomfort during the CHO-E trial period. This study once again emphasizes the importance on determining individualized hydration strategies.

Student athletes should avoid drinking sports drinks that contain over 6-8 grams of carbohydrates per serving. Excessive intake of carbohydrates during exercise can lead to gastrointestinal discomfort (AAP, 2011). Youth and adolescents should avoid drinking beverages that contain caffeine, high amounts of sugar, and carbonation. These drinks can cause side effects that include bloating, nausea, and restlessness at night (Bergeron, Waller, \& Marinik, 2006).

In addition to dehydration, student athletes should be educated on hyponatremia, or low sodium levels. Exercise associated with hyponatremia occurs when serum sodium levels drop 
below $135 \mathrm{mmol} / \mathrm{L}$. Endurance athletes, who exercise longer than 4 hours, are more susceptible to hyponatremia. Menstruating female athletes tend to be at a greater risk for developing hyponatremia because they have lower sweating rates, which can alters the body's response to rapid swelling (Hew-Butler et al, 2017). Data collected on runners in the 2002 Boston and 2006 London marathons found that $13 \%$ of the runners displayed asymptomatic hyponatremia. Many of the symptoms of hyponatremia resemble dehydration. These symptoms include muscle weakness, dizziness, coma, seizures, and death. Athletes should be aware of how much fluid they are consuming during practice to avoid both dehydration and hyponatremia (McDermott et al., 2017).

\section{Previous Literature on Hydration Studies in Youth Athletes}

Past studies on hydration status have indicated that adolescents are not the only ones inadequately hydrated. A review conducted by Nuccio et al. (2017) found that professional soccer players are failing to meet fluid recommendations. On average, soccer players lose more than $2 \%$ of their body weight during a 90-minute training period. However, soccer skills and cognition did not appear to be impaired when body weight losses where under $2.5 \%$. Other sports including American football, rugby, basketball, and tennis reported mild dehydration. Dehydration did not appear to inhibit performance until body mass losses were greater than $3 \%$ (Nuccio, Barnes, Carter, \& Baker, 2017).

Previous literature on hydration intake in adolescent athletes have focused on collecting data on junior athletes during practice. Many of the studies utilized pre/post body weight and urine specific gravity (USG) to gather information on hydration status. International studies have indicated that many athletes begin practice in a dehydrated state and maintain this status 
throughout practice and post-exercise (Arnaoutis et al., 2013; Arnaoutis et al., 2015; Gibson, Stuart-Hill, Pethick, \& Gaul, 2012; Phillips, Sykes, \& Gibson, 2014).

Gibson et al. (2012) found that $45 \%$ of the participants entered practice in a dehydrated state. The researchers observed 34 soccer players during practice. They recruited soccer players from three age groups and attended seven soccer practices. Their findings showed that one water break was allowed six of the seven practices and during one practice no water break was provided. Players' fluid intake was low, and they were unable to replace mean losses during practice. They found variability between sweat loses and fluid intake among the participants. This study suggested that hydration guidelines should be tailored to meet the individual needs of the athletes (Gibson, Stuart-Hill, Pethick, \& Gaul, 2012).

Phillips et al. (2014) and Arnaoutis et al. (2013) also found that soccer players were entering practice in a dehydrated state. A study on youth soccer players at summer camp found that $90 \%$ of the participants entered practice in a dehydrated state. Soccer players maintained this state throughout the camp. At the end of the first week, dehydration was observed in $97.2 \%$ of players. Even with fluids available, participants lost an average of -0.61 pounds. The researchers suggested that body weight loss many have occurred through involuntary dehydration (Arnaoutis et al., 2013). Involuntary dehydration occurs when the body is repeatedly exposed to stressors including exercise, hot environments, and dehydration. These stressors can delay the body's ability to replace fluid losses because the body's stimulus for thirst appears to be diminished (Greenleaf, 1992). Involuntary dehydration has been observed in other studies. Youth athletes were provided with available fluids and water breaks, but they were still not meeting fluid requirements (Arnaoutis et al. 2013). Coaches and athletic trainers should be diligent in reminding athletes to drink fluids. Results from studies on soccer players have suggested that 
more research needs to be conducted on hydration guidelines and athletes may benefit from education on hydration. The theme of adolescent athletes coming to practice in a dehydrated state is consistent throughout the literature. Studies on tennis players, football players, basketball and volleyball players found that these athletes are starting practice in a dehydrated state (Bergeron, Waller, \& Marinik, 2006; Kavouras et al., 2012; Yeargin et al., 2010).

Yeargin et al. (2010) targeted high school football players and found that most players could replenish fluid losses during practice. However, high school football players did fail to exercise proper rehydration strategies outside of practice. This resulted in players maintaining a mild dehydrated state throughout the pre-season workouts (Yeargin et al., 2010). One of the few studies that incorporated a hydration intervention noted increases in performance of adolescent volleyball players (Kavouras et al., 2012). These studies concluded that more strategies should be taken to educate athletes about pre/post training hydration tactics. This is one of the few studies that has observed student athletes.

Yeargin (2009) collaborated with researchers throughout the country to conduct a study on hydration status, sweat rates, and hydration education in youth football players. The football players were observed for five days during summer camp. Data was collected on their sweat rates and hydration status prior to administration of the study. A hydration questionnaire was also given to participants at the beginning of the study to assess their current understanding of their hydration habits and awareness. The football players were assigned to either an intervention or control group. Participants in the intervention group were provided with educational sessions on hydration after dinner on days 2-4 of the camp. These short educational sessions provided players with information on the importance of hydration, hydration indices, and ways to improve hydration status before and after practice. The control group was not provided with any extra 
information on hydration during the camp. The intervention group did a better job of maintaining their body weight and consuming fluids throughout the camp. Participants were able to replace fluid losses during practices but not on game days. Results showed that the participants were knowledgeable of their hydration habits, but campers noted that hydration may have been impaired by lack of water breaks and crowded water stations. This study suggests that youth athletes may be able to understand the importance of hydration but are unable to achieve a proper hydration status due to limited water breaks and recovery time (McDermott et al., 2009).

Many past studies on hydration have not compared hydration habits between males and females. Francescato et al. (2019) explored the hydration behaviors and pre/post-exercise differences in hydration status between adolescent female and male soccer players. In addition, they analyzed the effects of a personalized hydration session compared to ad libitum fluid session. The participants completed both sessions. There appears to be a striking difference between female and male soccer players regarding ad libitum fluid intake versus their personalized hydration strategies. Male soccer players drank significantly less water when they were instructed to drink water ad libitum compared to when they were given a personalized hydration plan. Whereas, female soccer players drank similar amounts of water in the ad libitum session and personalized hydration session. This data suggests that gender should be taken into consideration when developing a hydration plan (Francescato et al., 2019).

Very few studies have provided an educational intervention to teach athletes about hydration strategies. Three studies on adolescent athletes assessed whether an education intervention could improve fluid intake. Volleyball and basketball players in Greece were separated into a control and intervention group. The intervention group was provided with additional information on hydration throughout the study. This information included a one-hour 
lecture on the benefits of hydration, explanation of the urine color chart, and improved water accessibility. The participants were observed over five days. On the second day of the study, there appeared to be no differences in drinking habits between the control and intervention group. On the fourth day of the study, only $66.1 \%$ of the intervention group participants were classified as dehydrated compared to the control group where $96.7 \%$ of the participants were classified as dehydrated. Their findings showed that the hydration invention proved to be helpful in increasing fluid intake over a 2-day period. Athletes in the intervention group also had improved endurance performance (Kavouras et al., 2012).

Volleyball players in Hawaii were also provided with an educational session on hydration. The study was broken down into four observational periods. The first week was the control period when individual hydration habits and sweat rates were determined. At the end of the control period, an educational session on hydration was presented to the study participants, coaches, and parents. During the third week of the study, participants were provided with individualized hydration plans based on their sweat rates. Researchers required coaches to provide six water breaks during a 2-hour practice. The last part of the study was a follow-up session to conclude if any changes had been made to hydration habits. The one-day education session did not prove to be beneficial, but they did find that when participants were prescribed individual plans their fluid intake was improved. Adolescents may need repeated exposure to hydration information for it to be beneficial (Cleary et al., 2012).

A hydration intervention provided to 120 college athletes in India was shown to improve the knowledge, attitudes, and hydration practices of athletes. The athletes were placed in either a control or intervention group. A week before the study commenced, data was collected on the participants height, weight, BMI, and body composition. The intervention group was provided 
with a week-long hydration education program. The researchers covered topics including importance of fluids and its benefits, including dehydration, hydration status, and sports drinks. Each session ran for one hour. During the last week of the study, all participants were asked to complete a knowledge, attitudes, and hydration practices questionnaire (KAP). The intervention group had improved hydration knowledge, attitudes, and hydration practices overall. Females performed better on the KAP questionnaire, but males in the intervention group were less dehydrated than females. The control group found no differences between the male and female groups in regard to hydration. The results of this study showed that an intervention helped improve athletes' knowledge on hydration and hydration status (Sobana \& Mirmala-Many, 2012).

Previous research has validated the need to fill the gaps in the literature. Many studies have relied on short-term observations of hydration status in athletes and do not provide followup data. Future studies should include the coaches and parents during the intervention period. Educating coaches and parents may lead to improved hydration habits in adolescent athletes because they can better monitor the students drinking habits. These steps may help prevent heatrelated illness in adolescent athletes and prompt improved drinking behaviors in high school athletes. 


\section{REFERENCES}

American Academy of Pediatrics. (2011). Clinical report--sports drinks and energy drinks for children and adolescents: Are they appropriate? doi:10.1542/peds.2011-0965

Anastasiou, C. A., Kavouras, S. A., Arnaoutis, G., Gioxari, A., Kollia, M., Botoula, E., \& Sidossis, L. S. (2009). Sodium replacement and plasma sodium drop during exercise in the heat when fluid intake matches fluid loss. Journal of Athletic Training, 44(2), 117-123. doi:10.4085/1062-6050-44.2.117

Arnaoutis, G., Kavouras, S. A., Kotsis, Y. P., Tsekouras, Y. E., Makrillos, M., \& Bardis, C. N. (2013). Ad libitum fluid intake does not prevent dehydration in suboptimally hydrated young soccer players during a training session of a summer camp. International Journal of Sport Nutrition and Exercise Metabolism, 23(3), 245-251. doi:10.1123/ijsnem.23.3.245

Arnaoutis, G., Kavouras, S., Angelopoulou, A., Skoulariki, C., Bismpikou, S., Mourtakos, S., \& Sidossis, L. (2015). Fluid balance during training in elite young athletes of different sports. Journal of Strength and Conditioning Research, 29(12), 3447-3452. doi:10.1519/JSC.0000000000000400

Ayotte, J., David, \& Corcoran, M. P. (2018). Individualized hydration plans improve performance outcomes for collegiate athletes engaging in in-season training. Journal of the International Society of Sports Nutrition, 15(1), 27-10. doi:10.1186/s12970-018-0230-2

Benton, D., Young, H., \& Jenkins, K. (2015). The development of the predisposition to dehydration questionnaire. Appetite, 87, 76-80. doi:10.1016/j.appet.2014.11.029

Bergeron, M. F., Waller, J. L., \& Marinik, E. L. (2006). Voluntary fluid intake and core temperature responses in adolescent tennis players: Sports beverage versus water. British Journal of Sports Medicine, 40(5), 406-410. doi:10.1136/bjsm.2005.023333 
Bergeron, M. F., Devore, C., \& Rice, S. G. (2011). Policy statement--climatic heat stress and exercising children and adolescents. Pediatrics, 128(3), e741. doi:10.1542/peds.2011-1664

Casa, D. J., Csillan, D., Armstrong, L. E., Baker, L. B., Bergeron, M. F., Buchanan, V. M., . . . Yeargin, S. W. (2009). Preseason heat-acclimatization guidelines for secondary school athletics. Journal of Athletic Training, 44(3), 332-333. doi:10.4085/1062-6050-44.3.332

Cleary, M. A., Hetzler, R. K., Wasson, D., Wages, J. J., Stickley, C., \& Kimura, I. F. (2012a). Hydration behaviors before and after an educational and prescribed hydration intervention in adolescent athletes. Journal of Athletic Training, 47(3), 273-281. doi:10.4085/1062-605047.3.05

Cotugna, N., Vickery, C. E., \& McBee, S. (2005). Sports nutrition for young athletes. The Journal of School Nursing, 21(6), 323-328. doi:10.1177/10598405050210060401

Francescato, M. P., Venuto, I., Buoite Stella, A., Stel, G., Mallardi, F., \& Cauci, S. (2019). Sex differences in hydration status among adolescent elite soccer players. Journal of Human Sport and Exercise, 14(2) doi:10.14198/jhse.2019.142.02

Ganio, M. S., Tucker, M. A., Moyen, N. E., Butts, C. L., Treece, K., Burchfield, J. M., ... Smith, A. J. (2016). Effects of obesity and mild hypohydration on local sweating and cutaneous vascular responses during passive heat stress in females. Applied Physiology, Nutrition, and Metabolism, 41(8), 879-887. doi:10.1139/apnm-2016-0142

Gibson, J. C., Stuart-Hill, L. A., Pethick, W., \& Gaul, C. A. (2012). Hydration status and fluid and sodium balance in elite Canadian junior women's soccer players in a cool environment. Applied Physiology, Nutrition, and Metabolism = Physiologie Appliquee, Nutrition Et Metabolisme, 37(5), 931. doi:10.1139/H2012-073 
Hew-Butler, T., Loi, V., Pani, A., \& Rosner, M. H. (2017). Exercise-associated hyponatremia: 2017 update. Frontiers in Medicine, 4, 21. doi:10.3389/fmed.2017.00021

Kavouras, S. A., Arnaoutis, G., Makrillos, M., Garagouni, C., Nikolaou, E., Chira, O., .. . Sidossis, L. S. (2012a). Educational intervention on water intake improves hydration status and enhances exercise performance in athletic youth. Scandinavian Journal of Medicine \& Science in Sports, 22(5), 684-689. doi:10.1111/j.1600-0838.2011.01296.x

Leggett, T., Williams, J., Daly, C., Kipps, C., \& Twycross-Lewis, R. (2018). Intended hydration strategies and knowledge of exercise-associated hyponatraemia in marathon runners: A questionnaire-based study. Journal of Athletic Training, 53(7), 696-702. doi:10.4085/1062$6050-125-17$

Maughan, R. J., \& Shirreffs, S. M. (2010). Development of hydration strategies to optimize performance for athletes in high-intensity sports and in sports with repeated intense efforts. Scandinavian Journal of Medicine \& Science in Sports, 20, 59-69.

McDermott, B. P., Anderson, S. A., Armstrong, L. E., Casa, D. J., Cheuvront, S. N., Cooper, L., \&, Roberts, W. O. (2017). National athletic trainers' association position statement: Fluid replacement for the physically active. Journal of Athletic Training, 52(9), 877-895. doi:10.4085/1062-6050-52.9.02

McDermott, B. P., Casa, D. J., Yeargin, S. W., Ganio, M. S., Lopez, R. M., \& Mooradian, E. A. (2009). Hydration status, sweat rates, and rehydration education of youth football campers. Journal of Sport Rehabilitation, 18(4), 535-552. doi:10.1123/jsr.18.4.535

Meyer, F., Volterman, K. A., Timmons, B. W., \& Wilk, B. (2012). Fluid balance and dehydration in the young athlete.American Journal of Lifestyle Medicine, 6(6), 489-501. doi:10.1177/1559827612444525 
National Federation of State High School Associations (NFHS). (2018). High School Sports Participation Increases for 29th Consecutive Year. Retrieved from: https://www.nfhs.org/articles/high-school-sports-participation-increases-for-29thconsecutive-year/

Nuccio, R., Barnes, K., Carter, J., \& Baker, L. (2017). Fluid balance in team sport athletes and the effect of hypohydration on cognitive, technical, and physical performance. Sports Medicine, 47(10), 1951-1982. doi:10.1007/s40279-017-0738-7

Phillips, S. M., Sykes, D., \& Gibson, N. (2014). Hydration status and fluid balance of elite European youth soccer players during consecutive training sessions. Journal of Sports Science \& Medicine, 13(4), 817-822. Retrieved from https://www.ncbi.nlm.nih.gov/pubmed/25435774

Poole, J. A., Stearns, R. L., \& Lopez, R. M. (2017). Heat acclimatization and exertional heat illness prevention in youth football programs. Strength and Conditioning Journal, 39(2), 69-

Rowland, T. (2011). Fluid replacement requirements for child athletes. Sports Medicine, 41(4), 279-288. doi:10.2165/11584320-000000000-00000

Sawka, M. N., Burke, L. M., Eichner, E. R., Maughan, R. J., Montain, S. J., \& Stachenfeld, N. S. (2007). American college of sports medicine position stand. exercise and fluid replacement. Medicine and Science in Sports and Exercise, 39(2), 377. Retrieved from https://www.ncbi.nlm.nih.gov/pubmed/17277604

Sawka, M. N., Cheuvront, S. N., \& Carter, R. (2005). Human water needs. Nutrition Reviews, 63(6 Pt 2), S39. doi:10.1111/j.1753-4887.2005.tb00152.x

Sobana, R.M., \& Nirmala-Many, J. (2014). Effect of Hydration Education on College Athlete's Hydration Status and KAP. International Journal of Science and Research, 3(7). 
Thomas, T., Erdman, K.A., \& Burke, L.M. (2016). Position of the academy of nutrition and dietetics, dietitians of Canada, and the American college of sports medicine: Nutrition and athletic performance. Journal of the Academy of Nutrition and Dietetics, 116(3), 501-528. doi:10.1016/j.jand.2015.12.006

Trammell, J. E. (2007). Assessment of hydration knowledge, attitude, behaviors and fluid replacement effectiveness of collegiate athletes Available from ProQuest Central (Alumni Edition). Retrieved from https://search.proquest.com/docview/304886272

Wall, B. A., Watson, G., Peiffer, J. J., Abbiss, C. R., Siegel, R., \& Laursen, P. B. (2015). Current hydration guidelines are erroneous: Dehydration does not impair exercise performance in the heat. British Journal of Sports Medicine, 49(16), 1077-1083. doi:10.1136/bjsports-2013092417

Yard, E. E., Gilchrist, J., Haileyesus, T., Murphy, M., Collins, C., McIlvain, N., \& Comstock, R. D. (2010). Heat illness among high school athletes — United States, 2005-2009. Journal of Safety Research, 41(6), 471-474. doi:10.1016/j.jsr.2010.09.001

Yeargin, S. W., Casa, D. J., Judelson, D. A., McDermott, B. P., Ganio, M. S., Lee, E. C., . . Maresh, C. M. (2010). Thermoregulatory responses and hydration practices in heatacclimatized adolescents during preseason high school football. Journal of Athletic Training, 45(2), 136-146. doi:10.4085/1062-6050-45.2.136 


\section{APPENDIX A: HYDRATION QUESTIONNAIRE}

Code:

ID:

Pre-Survey: Hydration Questionnaire

1. Male

Female

2. What high school do you attend?

3. What sport do you play?

4. Indicate year in school
a. Freshman
b. Sophomore
c. Junior
d. Senior

5. On average, how many hours a day do you practice? (**Circle One**)
a. $<3$ hours
b. 3-5 hours
c. 5-7 hours
d. $>7$ hours

6. How would you rate the intensity of your practices?(** Circle One**)
a. Very Low
b. Low
c. Moderate
D. High

The next section consists of a series of true and false questions. Read each statement carefully and circle the best answer.

1. Thirst is the best gauge of dehydration.
a. True
b. False 
2. Dehydration decreases athletic performance
a. True
b. False

3. An athlete should not drink water or any fluids during practice
a. True
b. False

4. Excessive sweating, thirst, and cramping are signs of dehydration
a. True
b. False

5. Sports drinks are better than water because they contain carbohydrates
a. True
b. False

6. An athlete should drink 2-3 glasses of water or sports drinks several hours before competition
a. True
b. False

7. A good way for an athlete to determine how much fluids to consume after practice is to weight before and after practice
a. True
b. False

8. I believe I am hydrated when I start practice
a. True
B. False

9. How many glasses of water do you drink per day?

10. How many water bottles ( $32 \mathrm{oz})$ do you drink during practice?

11. Where do you receive most of your information regarding hydration? 
Code:

ID:

Post-Survey: Hydration Questionnaire

1. On average, how many hours a day do you practice? (**Circle One**)
a. $<3$ hours
b. 3-5 hours
c. 5-7 hours
d. $>7$ hours

2. How would you rate the intensity of your practices? (** Circle One**)
a. Very Low
b. Low
c. Moderate
D. High

The next section consists of a series of true and false questions. Read each statement carefully and circle the best answer.

1. Thirst is the best gauge of dehydration.
a. True
b. False

2. Dehydration decreases athletic performance
a. True
b. False

3. An athlete should not drink water or any fluids during practice
a. True
b. False

4. Excessive sweating, thirst, and cramping are signs of dehydration
a. True
b. False

5. Sports drinks are better than water because they contain carbohydrates
a. True
b. False

6. An athlete should drink 2-3 glasses of water or sports drinks several hours before competition
a. True
b. False 
7. A good way for an athlete to determine how much fluids to consume after practice is to weight before and after practice
a. True
b. False

8. I believe I am hydrated when I start practice
a. True
B. False

9. How many glasses of water do you drink per day?

10. How many water bottles ( $32 \mathrm{oz})$ do you drink during practice?

11. Where do you receive most of your information regarding hydration? 


\section{APPENDIX B: MATERIALS FOR EDUCATIONAL SESSIONS}

Slide 1

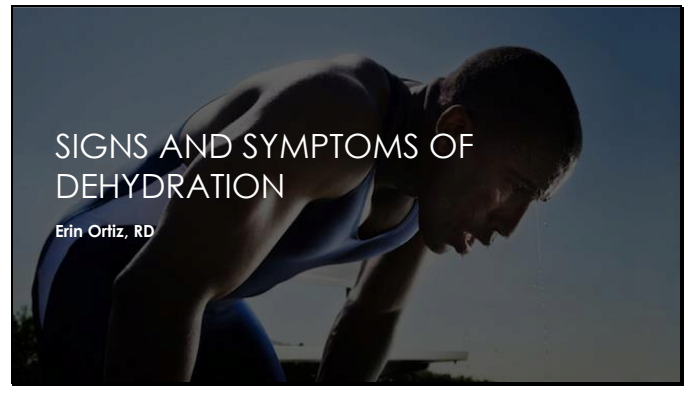

Slide 2

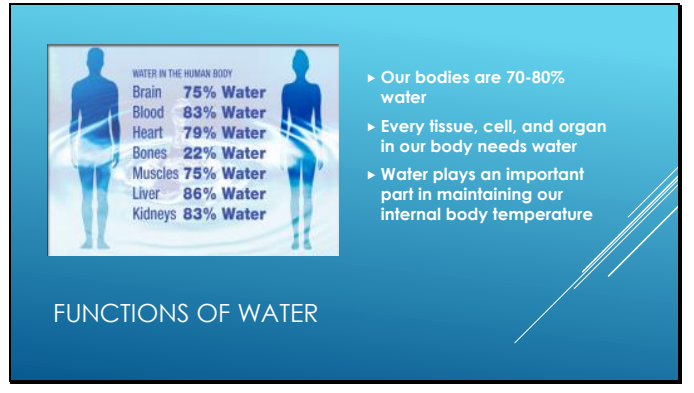

Functions of water:

Maintain homeostasis

Water helps transport nutrients and oxygen

Moistens body tissues (eyes, mouth, skin)

Main part of all body fluids (Duyff, 2012)

Slide 3

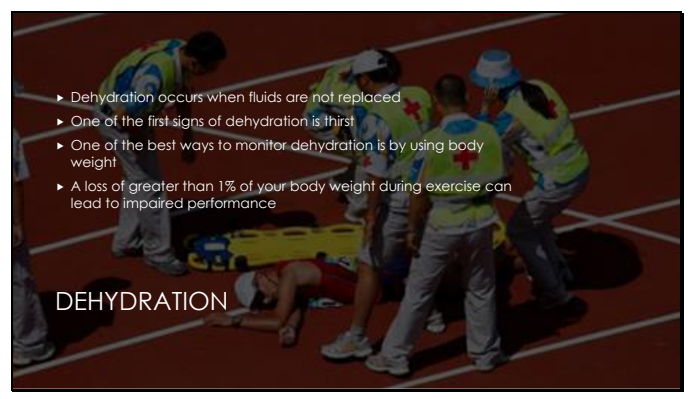

We will be looking at your body weight to help monitor dehydration. We will be measuring your pre/post body weights during practice. 
Slide 4

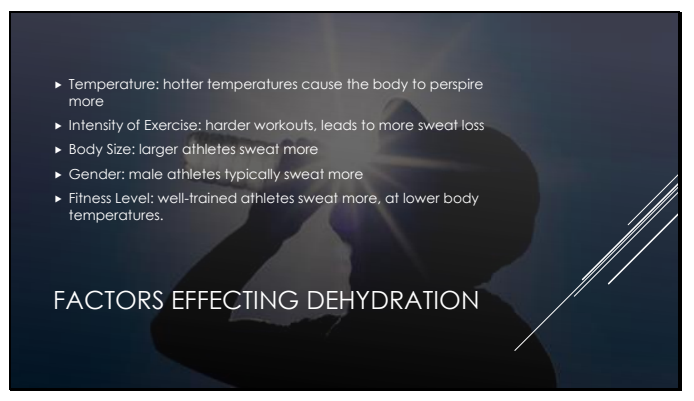

Sowell Jennings and Nelson Steen, 1995

Slide 5

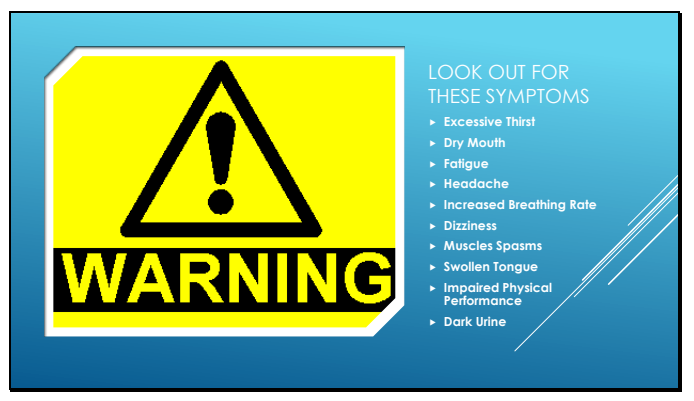

https://www.youtube.com/watch? v=A LHObkStAt0 (tennis video at 0.59) Go over Urine Colors

Slide 6

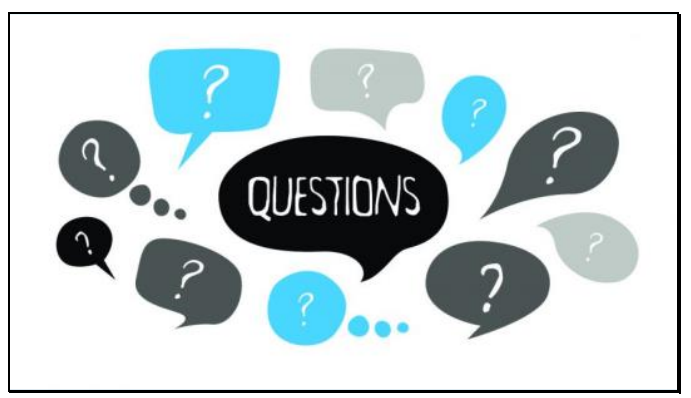


Slide 1

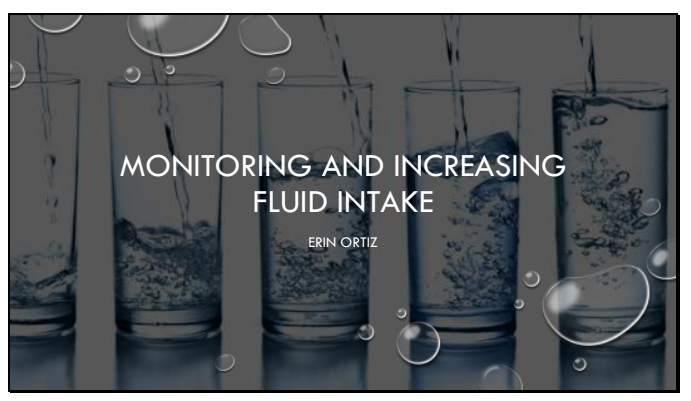

Slide 2

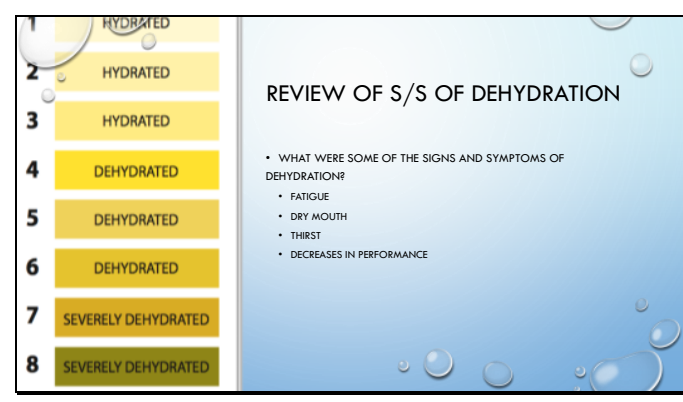

Urine Color Chart [online image]. (2018). Retrieved from: https://www.quora.com/Howdangerous-is-a-peach-colored-urine.

Slide 3

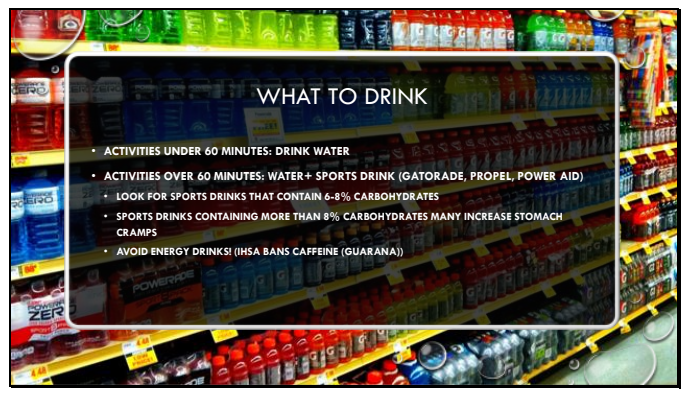

If a student is working out for less than 60 minutes, but it is hot and humid outside, add a sports drink If students are working out leisurely they most likely will only need water Avoid energy drinks, they are full of sugar and some may contain high amounts of caffeine (students need to be aware of IHSA rules on caffeine consumption) 
Slide 4

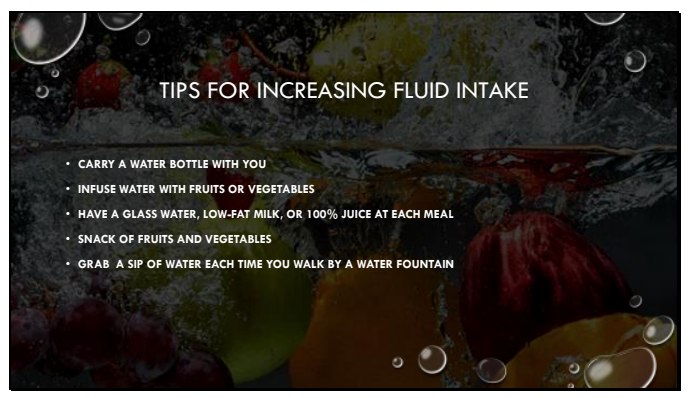

Many Fruits and Vegetables are high in water content

Other Foods also contain water

Slide 5

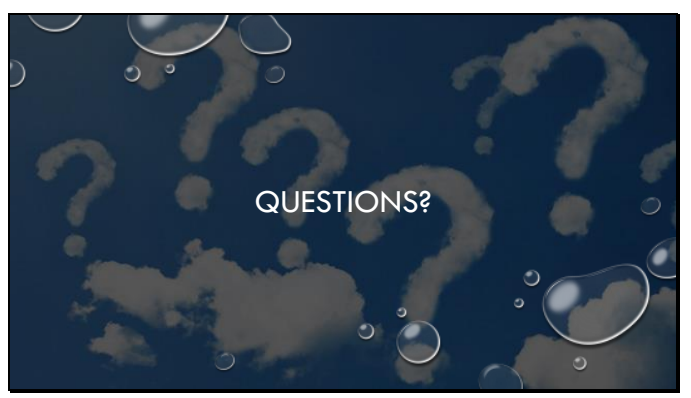

